\title{
History of Medical Treatment Absent
}

National Cancer Institute

\section{Source}

National Cancer Institute. History of Medical Treatment Absent. NCI Thesaurus. Code C160180.

An indication that a history of medical treatment is absent. 